\title{
Penerapan K-Means pada Pengelompokan Penjualan Produk Smartphone
}

\author{
Fatimah Putri Arfani Hasibuan ${ }^{1^{*}}$, Sumarno Sumarno ${ }^{2}$, Iin Parlina ${ }^{3}$ \\ ${ }^{1,2}$ Program Studi Teknik Informatika, STIKOM Tunas Bangsa, Pematangsiantar \\ ${ }^{3}$ Program Studi Komputerisasi Akuntansi, AMIK Tunas Bangsa, Pematangsiantar \\ Email: ${ }^{1 *}$ fatimahputriarfanihasibuan@gmail.com
}

\begin{abstract}
The development of smartphone technology companies that are increasingly rapidly today has more or less led to competition between these companies, thus requiring developers to find strategies or patterns that can increase product sales and marketing, as is the case at PT. Vivo Communication Indonesia Pematangsiantar branch. One of the strategies is to utilize transaction data by grouping them to see which products are more salable in the market and which are not, so that evaluations can be made in planning the next Vivo product promotion. The clustering method in this study uses the K-Means Clustering method. The K-Means method is a data mining method that is able to group some data into certain parts. In this paper the sales data that has been obtained will be divided into 3 groups, namely low sales, medium sales and high sales. Based on the results of testing using the K-Means method on Vivo smartphone sales data, it was found that the highest sales group had only 1 data, namely Vivo Y12 3+32GB. So it can be concluded that the K-Means method can be applied to group Vivo smartphone sales, because it is in accordance with the actual sales results.
\end{abstract}

Keywords: Clustering, Sales, Vivo, Data Mining, K-Means.

\begin{abstract}
ABSTRAK
Perkembangan perusahaan teknologi Smartphone yang semakin pesat dewasa ini sedikit banyaknya menimbulkan persaingan diantara perusahaan tersebut, sehingga menuntut para pengembang untuk menemukan strategi atau suatu pola yang dapat meningkatkan penjualan dan pemasaran produk, seperti halnya pada PT. Vivo Communication Indonesia cabang Pematangsiantar. Salah satu strateginya adalah memanfaatkan data transaksi dengan melakukan pengelompokkan untuk melihat produk mana yang lebih laku dipasaran dan mana yang tidak, agar dapat dilakukan evaluasi dalam perencanaan promosi produk Vivo selanjutnya. Metode pengelompokkan pada penelitian ini menggunakan metode Clustering K-Means. Metode K-Means adalah metode data mining yang mampu mengelompokkan beberapa data menjadi bagian-bagian tertentu. Pada makalah ini data penjualan yang telah diperoleh akan dibagi menjadi 3 kelompok yaitu penjualan rendah, penjualan sedang dan penjualan tinggi. Berdasarkan hasil Pengujian menggunakan metode K-Means terhadap data penjualan smartphone Vivo, diperoleh bahwa penjualan kelompok tertinggi hanya ada 1 data, yakni Vivo Y12 3+32GB. Sehingga dapat disimpulkan bahwa metode K-Means dapat diterapkan untuk melakukan pengelompokkan penjualan smartphone Vivo, karena sesuai dengan hasil penjualan yang sebenarnya..
\end{abstract}

Kata Kunci: Pengelompokkan, Penjualan, Vivo, Data Mining, K-Means

\section{Pendahuluan}

Perkembangan pengguna smartphone dari tahun ke tahun semakin meningkat di Indonesia. Hal ini tidak lepas menjamurnya berbagai varian smartphone. Pada Era revolusi Industri 4.0 ini, smartphone sudah menjadi industri bisnis yang diperhitungkan karena cukup menguntungkan. Sehingga persaingan pasar smartphone semakin lama semakin ketat [1]. Sehingga tidak mengherankan apabila banyak sekali beredar merek smartphone. Banyak produsen baru yang muncul menyajikan produk unggulannya. Hampir setiap waktu, para produsen smartphone ini selalu melakukan inovasi, seperti halnya PT. Vivo Communication Indonesia cabang Pematangsiantar. Jika tidak, tentu hal itu dapat menjadikan awal kehancuran dari bisnis tersebut. Memasuki pertengahan Juli 2021, sejumlah Lembaga riset mulai mengeluarkan laporan kuartal kedua pasar smartphone dunia, salah satunya Canalys. Berdasarkan laporan terbaru Canalys pada Quartile 2 tahun 2021, tercatat bahwa smartphone global 
pengiriman nya meningkat $12 \%$, ketika diseluruh dunia Beberapa penelitian terdahulu yang berhubungan mulai menggunakan, dan mulai terbentuknya kebiasaan dengan topik ini diantaranya: Penelitian untuk warga maupun ekonomi negara. Canalys menjabarkan mengelompokan Laju Pertumbuhan PDRB Kota lima besar vendor smartphone global berturut-turut Surabaya menggunakan Metode K-Means. Data dibagi pada kuartal 2 tahun 2021 antara lain: Samsung (19\%), menjadi 3 cluster: tinggi, sedang dan rendah. Hasil Xiaomi (17\%), Apple (14\%), Oppo (10\%), dan Vivo yang diperoleh terdapat 9 kategori/sektor dengan (10\%) [2]. Berdasarkan data tersebut, maka PT. Vivo klaster tinggi, 5 kategori/sektor dengan klaster sedang perlu menemukan strategi atau suatu pola yang mampu dan 3 kategori/sektor dengan klaster rendah [23]. meningkatkan jumlah penjualan serta pemasaran Selanjutnya penelitian yang dilakukan untuk produk mereka dimasa masa berikutnya. Salah satu mengelompokkan jumlah kasus terkonfirmasi Covid-19 strateginya adalah memanfaatkan data transaksi dengan dan jumlah kematian akibat virus ini di Asia Tenggara. melakukan pengelompokkan untuk melihat produk Data yang digunakan adalah data statistik negara Vivo mana yang banyak terjual dipasaran dan mana berdasarkan area kasus COVID-19 yang dikonfirmasi yang tidak, agar dapat dilakukan evaluasi dalam dan tercatat pada laboratorium, serta kematian pada perencanaan promosi produk Vivo selanjutnya.

Banyak metode-metode yang menjadi alternatif untuk membantu penentu kebijakan, salah satunya dengan menggunakan Data Mining [3]-[10]. Pada sektor pemasaran/penjualan, data mining umunya dimanfaatkan untuk target pemasaran (target penjualan), hubungan manajemen pelanggan (CRM), analisa pasar, cross selling hingga melakukan segmentasi pasar. Seperti menemukan kelompok/model pelanggan yang mempunyai karakteristik yang sama: minat, tingkat penghasilan, kebiasaan untuk berbelanja, dll. Selain itu untuk menentukan pelanggan yang memiliki pola pembelian dari waktu ke waktu. Menemukan hubungan / keterkaitan antar produk yang dijual, maupun prediksi berlandaskan asosiasi tersebut bulan April 2020 dari WHO (Kesehatan Dunia Organisasi). Pada penelitian ini Data dibagi menjadi 3 cluster: tinggi (C1), sedang (C2) dan rendah (C3). Hasil yang diperoleh terdapat empat negara dengan cluster level tinggi (C1), satu negara dengan cluster level sedang (C2), dan 6 negara dengan cluster level rendah (C3) [24]. Berikutnya adalah penelitian menggunakan metode K-Means untuk mengelompokkan penjualan paket data telkomsel. Data penjualan dari penelitian ini dikelompokkan menjadi 3 bagian, antara lain: penjualan rendah, penjualan sedang dan penjualan tinggi. Pengujian clustering menggunakan K-Means terhadap data penjualan paket telkomsel, menghasilkan persentase kesesuaian $100 \%$ dibandingkan pengelompokkan manual [25].

serta jenis pelanggan apa yang membeli produk apa, Hal-hal terkait tersebut yang melatar belakangi karena salah satu keunggulan data mining mampu dilakukannya penelitian ini dengan menggunakan melakukan pengelompokan [11]-[14] maupun metode K-Means, karena Metode K-Means mudah klasifikasi [15]-[19], hingga identifikasi produk terbaik untuk diimplementasikan dan dijalankan, waktu yang untuk berbagai kelompok pelanggan, memprediksi diperlukan untuk pembelajaran relatif cepat serta faktor apa yang akan menarik pelanggan baru, mudah untuk diadaptasi.

penyediaan informasi ringkasan, laporan ringkasan multidimensi, Informasi ringkasan statistik 2. Metode Penelitian (kecenderungan dan variasi pusat data). Akan tetapi banyak nya metode Data Mining yang dapat digunakan

\subsection{Lokasi dan Waktu Penelitian}

untuk mengatasi masalah pengelompokkan seperti K- Data Penelitian diperoleh dari semua Store yang Means [20], K-Medoids [21], X-Means [22], bekerjasama dengan PT. Vivo yang ada dikota menimbulkan kebingungan tersendiri bagi pengambil Pematangsiantar. Waktu pengumpulan data dilakukan kebijakan di PT. Vivo Communication Indonesia selama bulan April sampai dengan bulan Juni 2020. cabang Pematangsiantar. Sehingga pada makalah ini diusulkan pengelompokkan data penjualan smartphone Vivo menggunakan metode K-Means.

Tabel 1. Data Penjualan Vivo

\begin{tabular}{ccrrr}
\hline No & Type Smartphone Vivo & Bulan April 2020 & Bulan Mei 2020 & Bulan Juni 2020 \\
\hline 1 & S1 Pro 8+128 & 23 & 7 & 2 \\
2 & V17 Pro & 4 & 3 & 6 \\
3 & V19 8+128GB & 113 & 95 & 88 \\
4 & V19 8+256GB & 9 & 6 & 9 \\
5 & Y11 2+32GB & 71 & 117 & 98 \\
6 & Y12 3+32GB & 996 & 1154 & 1133 \\
7 & Y12 3+64GB & 5 & 1 & 25 \\
8 & Y154+64 GB & 159 & 194 & 271 \\
\hline
\end{tabular}

DOI: $\mathrm{xxxx}$

Lisensi: Creative Commons Attribution 4.0 International (CC BY 4.0) 


\begin{tabular}{rrrrr}
\hline 9 & Y17 4+128GB & 162 & 88 & 12 \\
10 & Y19 6+128GB & 106 & 72 & 34 \\
11 & Y30 4+128GB & 37 & 237 & 330 \\
12 & Y50 8+128GB & 526 & 91 & 188 \\
13 & Y91C 2+32GB & 3 & 213 & 522 \\
\hline
\end{tabular}

Tabel 1 adalah data tabel penjualan Smartphone Vivo yang dikumpulkan dari semua Gerai HP di Pematangsiantar yang merupakan mitra PT. Vivo Communication Indonesia.

\subsection{Flowchart Penelitian}

Berikut ini akan disajikan Flowchart penelitian menggunakan metode K-Means.

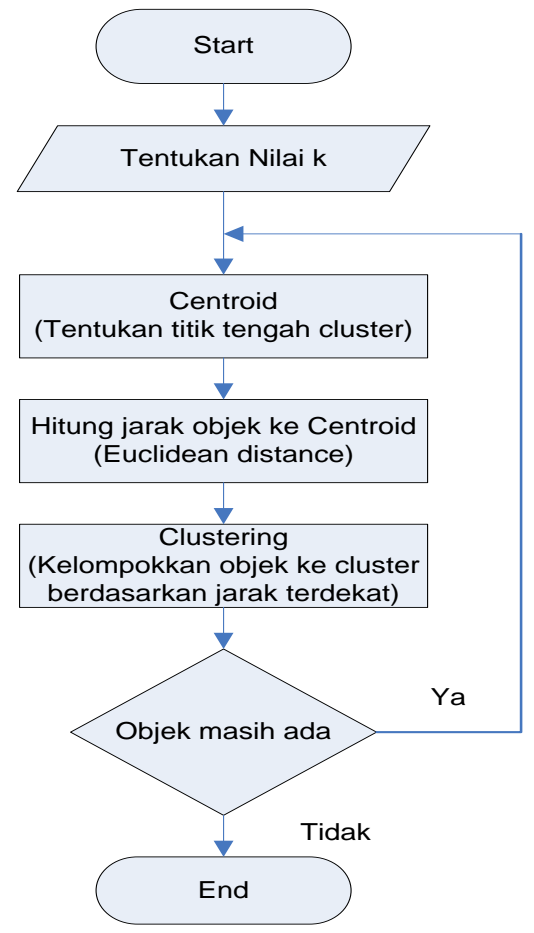

Gambar 1. Diagram alir dari metode Clustering K-Means [26]

Tahapan demi tahapan metode K-Means sebagai berikut [8], [27]-[30]:

1. Atur jumlah cluster (k) pada data set.

2. Atur nilai pusat (Centroid).

Pada tahap awal Pengaturan nilai Centroid dilakukan secara acak. Pada tahap iterasi digunakan rumus persamaan (1) seperti berikut.

$\mathrm{V}_{\mathrm{ij}}=\frac{1}{N i} \sum_{k=0}^{N i} X k j$

Keterangan :

$\mathrm{V}_{\mathrm{ij}}=$ Centroid rata-rata cluster $\mathrm{ke}-\mathrm{I}$ variabel ke- $\mathrm{j}$

$\mathrm{N}_{\mathrm{i}} \quad$ Jumlah anggota cluster ke-i

$\mathrm{i}, k=$ Indeks cluster

$\mathrm{j} \quad=$ Indeks variabel

$\mathrm{Xkj}=$ nilai ke-k variabel ke-j untuk cluster

3. Berdasarkan masing-masing record, jarak terdekat dihitung dengan Centroid.

Beberapa cara yang biasa digunakan untuk melakukan pengukuran jarak data ke pusat cluster, diantaranya Euclidean, Manhattan/City Block, dan Minkowsky. Setiap cara memiliki kelebihan dan kekurangan masing-masing. Untuk penulisan pada bab ini, jarak Centroid yang digunakan adalah Euclidean Distance, dengan rumus seperti dibawah ini:

$D e=$

$\sqrt{(x i-s i)^{2}+(y i-t i)^{2}}$.

Keterangan :

De = Distance Euclidean

i $\quad=$ Jumlah objek $^{2}$

$(\mathrm{x}, \mathrm{y}) \quad=$ Koordinat objek

$(\mathrm{s}, \mathrm{t}) \quad=$ Koordinat Centroid

4. Kelompokkan objek berdasarkan jarak ke Centroid terdekat

5. Ulangi langkah ke-3 hingga langkah ke-4, lakukan iterasi hingga Centroid bernilai optimal

\section{Hasil dan Pembahasan}

\subsection{Penentuan Centroid}

Penentuan pusat awal Cluster (Centroid) ditentukan secara manual atau random yang diambil dari data yang ada dalam range. Nilai Cluster 0 diambil dari data paling rendah $(\mathrm{C} 1)$, Nilai Cluster 1 diambill dari data acak atau yang paling tengah/sedang (C2) dan Nilai Cluster 2 diambil dari data yang paling tertinggi (max).

\begin{tabular}{ccccc}
\multicolumn{5}{c}{ Tabel 2. Centroid Awal } \\
\hline \multirow{3}{*}{ Centroid } & C1 (Min) & 4 & 3 & 6 \\
& C2 (Ave) & 159 & 194 & 271 \\
& C3 (Max) & 996 & 1154 & 1133 \\
\hline
\end{tabular}

\subsection{Mengitung Jarak Centroid}

Perhitungan jarak antara titik Centroid dengan titik tiap objek menggunakan rumus Euclidian Distance. (Persamaan 1). Sehingga menghasilkan Jarak dari Centroid yang disajikan pada Tabel 3 .

\begin{tabular}{cccc}
\multicolumn{4}{c}{ Tabel 3. Hasil Perhitungan Iterasi 1 } \\
\hline C1 & C2 & C3 & Jarak Terpendek \\
\hline 19,82423 & 354,7196 & 1881,887 & 19,8242276 \\
0 & 361,5674 & 1891,823 & 0 \\
164,5266 & 213,0868 & 1730,085 & 164,5265936 \\
6,557439 & 355,6515 & 1885,59 & 6,557438524 \\
161,0869 & 208,8109 & 1732,691 & 161,0869331 \\
1891,823 & 1537,925 & 0 & 0 \\
19,13113 & 348,5412 & 1881,264 & 19,13112647 \\
361,5674 & 0 & 1537,925 & 0 \\
179,5132 & 279,8678 & 1757,428 & 179,5132307 \\
126,2894 & 271,7756 & 1780,625 & 126,2893503 \\
401,0249 & 142,1759 & 1550,928 & 142,1759473 \\
559,7785 & 390,1115 & 1497,963 & 390,1115225 \\
\hline
\end{tabular}

DOI: $\mathrm{xxxx}$

Lisensi: Creative Commons Attribution 4.0 International (CC BY 4.0) 


\begin{tabular}{cccc}
\hline C1 & C2 & C3 & Jarak Terpendek \\
\hline 557,0969 & 296,1385 & 1498,283 & 296,1384811 \\
\hline
\end{tabular}

\subsection{Menentukan Pengelompokan (Cluster)}

Penentuan kelompok dilakukan dengan mencari nilai kelompok berdasarkan nilai minimal dari nilai kelompok dan diletakkan pada kelompok yang sesuai dengan nilai minimal pada Iterasi 1.

\begin{tabular}{ccccc}
\multicolumn{6}{c}{ Tabel 4. Cluster Iterasi 1} \\
\hline No & Type & C1 & C2 & C3 \\
\hline 1 & S1 Pro 8+128 & 1 & & \\
2 & V17 Pro & 1 & & \\
3 & V19 8+128GB & 1 & & \\
4 & V19 8+256GB & 1 & & \\
5 & Y11 2+32GB & 1 & & \\
6 & Y12 3+32GB & & & 1 \\
7 & Y12 3+64GB & 1 & & \\
8 & Y154+64 GB & & 1 & \\
9 & Y17 4+128GB & 1 & & \\
10 & Y19 6+128GB & 1 & & \\
11 & Y30 4+128GB & & 1 & \\
12 & Y50 8+128GB & & 1 & \\
13 & Y91C 2+32GB & & 1 & \\
\hline
\end{tabular}

Selanjutnya dalam metode K-Means, perhitungan berhenti apabila Cluster pada iterasi yang dihasilkan sama pada iterasi sebelumnya. Maka pencarian kelompok pada iterasi selanjutnya hingga sama nilai iterasinya. Mencari nilai Centroid berikutnya dengan menggunakan Centroid baru berdasarkan Iterasi ke-1 dengan menjumlahkan nilai sesuai yang tertera pada kelompok di tabel 3. Adapun Centroid baru untuk mencari Cluster selanjutnya adalah dengan menjumlahkan nilai yang terpilih pada Cluster tersebut kemudian membagikannya sebanyak jumlah nilai.

Tabel 5. Centroid Baru Iterasi 2

\begin{tabular}{ccccc}
\hline \multirow{4}{*}{ Centroid } & C1 (Min) & 61,625 & 48,625 & 34,25 \\
& C2 (Ave) & 181,25 & 183,75 & 327,75 \\
& C3 (Max) & 996 & 1154 & 1133 \\
\hline
\end{tabular}

Berikutnya adalah perhitungan jarak antara titik Centroid dengan titik tiap objek, juga menggunakan rumus Euclidian Distance (Persamaan 1). Sehingga menghasilkan Jarak dari Centroid yang disajikan pada Tabel 6.

Tabel 6. Hasil Perhitungan Iterasi 2

\begin{tabular}{cccc}
\hline $\mathbf{C 1}$ & $\mathbf{C 2}$ & $\mathbf{C 3}$ & Jarak Terpendek \\
\hline 65,304 & 402,985 & 1881,887 & 65,304 \\
78,742 & 409,403 & 1891,823 & 78,742 \\
87,630 & 264,603 & 1730,085 & 87,630 \\
72,276 & 403,567 & 1885,590 & 72,276 \\
93,953 & 263,431 & 1732,691 & 93,953 \\
1817,185 & 1501,210 & 0,000 & 0,000 \\
74,566 & 395,119 & 1881,264 & 74,566 \\
294,391 & 61,812 & 1537,925 & 61,812 \\
110,094 & 330,510 & 1757,428 & 110,094 \\
50,156 & 323,171 & 1780,625 & 50,156 \\
\hline
\end{tabular}

\begin{tabular}{cccc}
\hline C1 & C2 & C3 & Jarak Terpendek \\
\hline 351,510 & 153,781 & 1550,928 & 153,781 \\
490,998 & 383,386 & 1497,963 & 383,386 \\
518,031 & 265,258 & 1498,283 & 265,258
\end{tabular}

Berdasarkan tabel jarak Centroid diatas, maka Cluster atau pengelompokkan Iterasi ke-2 dapat dilihat pada tabel 7.

Tabel 7. Cluster Iterasi 1

\begin{tabular}{ccccc}
\hline No & Type & C1 & C2 & C3 \\
\hline 1 & S1 Pro 8+128 & 1 & & \\
2 & V17 Pro & 1 & & \\
3 & V19 8+128GB & 1 & & \\
4 & V19 8+256GB & 1 & & \\
5 & Y11 2+32GB & 1 & & \\
6 & Y12 3+32GB & & & 1 \\
7 & Y12 3+64GB & 1 & & \\
8 & Y154+64 GB & & 1 & \\
9 & Y17 4+128GB & 1 & & \\
10 & Y19 6+128GB & 1 & & \\
11 & Y30 4+128GB & & 1 & \\
12 & Y50 8+128GB & & 1 & \\
13 & Y91C 2+32GB & & 1 & \\
\hline
\end{tabular}

Tabel Cluster Iterasi ke-1 dan tabel Cluster Iterasi ke-2 memiliki nilai Cluster yang sama atau tidak berubah pada Cluster Iterasi ke-2 maka perhitungan dihentikan dan hasil yang diperoleh yaitu :

1. Cluster 1 (C1) memiliki 8 data yang diartikan bahwa kelompok pertama adalah kategori penjualan terendah pada bulan April, Mei, Juni Tahun 2020 yaitu Handphone Vivo dengan merk sebagai berikut : S1 Pro 8+128, V17 Pro, V19 8+128GB, V19 $8+256 \mathrm{~GB}, \quad \mathrm{Y} 11 \quad 2+32 \mathrm{~GB} \quad \mathrm{Y} 11 \quad 2+32 \mathrm{~GB}, \quad \mathrm{Y} 12$ 3+64GB, Y17 4+128GB, Y19 6+128GB.

2. Cluster 2 (C2) memiliki 4 data yang diartikan bahwa kelompok kedua adalah kategori penjualan sedang pada bulan April, Mei, Juni Tahun 2020 yaitu Handphone Vivo dengan merk sebagai berikut: Y154+64 GB, Y30 4+128GB, Y50 8+128GB, Y91C 2+32GB.

3. Cluster 3 (C3) memiliki 1 data yang diartikan bahwa kelompok ketiga adalah kategori penjualan tertinggi pada bulan April, Mei, Juni Tahun 2020 yaitu Handphone Vivo dengan merk Y12 3+32GB

\subsection{Implementasi dengan Rapidminer}

Berikut adalah proses pengelompokkan dan hasil dari metode K-Means yang dilakukan dengan Rapidminer.. 


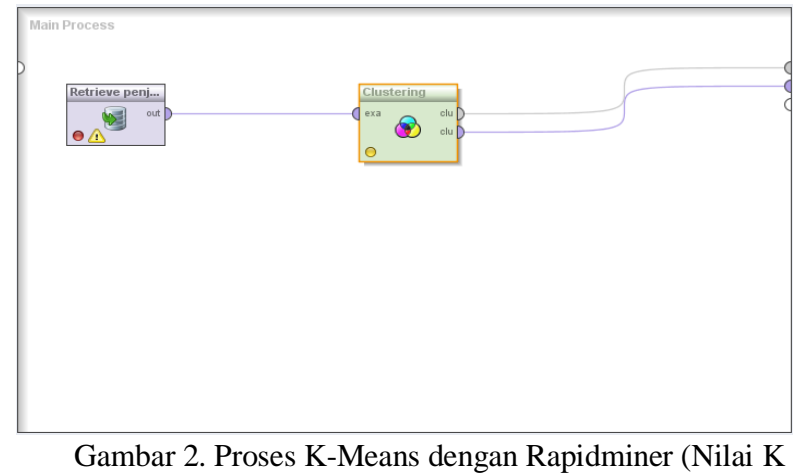
$=3$ )

Gambar 2 menjelaskan proses pengelompokkan atau pengklusteran metode K-means dengan menggunakan Rapidminer yang diawali dengan mengimport data excel Penjualan Smartphone di Pematangsiantar, kemudian dilanjutkan dengan pemilihan operator metode K-means untuk pengklasterannya. Nilai $\mathrm{k}=3$, measure types yang digunakan adalah MixedMeasures. Setelah itu dihubungkan ke operator Apply Model untuk menerapkan model yang sudah dipelajari atau dilatih. Tujuannya adalah untuk mendapatkan prediksi pada unlabeled data (data testing) yang belum memiliki label. Tahap berikutnya adalah menghubungkan ke operator Performance untuk mengevaluasi kinerja model yang memberikan daftar nilai kriteria kinerja secara otomatis sesuai dengan tugas yang diberikan. Hasil nya dapat dilihat pada gambar 3, gambar 4, gambar 5, gambar 6 dan gambar 7 .

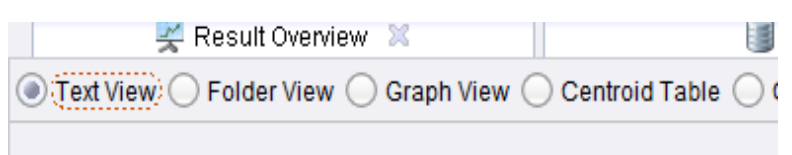

\section{Cluster Model}

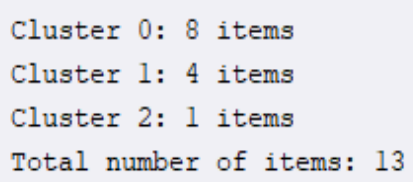

Gambar 3. Hasil Cluster

Berdasarkan gambar 3 dapat dijelaskan bahwa dari tiga cluster yang dihasilkan terdapat 8 items untuk Cluster_0 (C1), 4 items untuk Cluster_1 (C2) dan 1 items untuk Cluster_2 (C3). Untuk hasil akhir Centroid table dapat dilihat pada gambar 4. Sedangkan hasil plot view cluster penjualan smartphone Vivo disajikan pada gambar 5 .

Gambar 5 berikut menjelaskan bahwa titik warna biru merupakan kelompok Cluster_0 (Penjualan rendah) yang terdiri dari 4 items. Titik warna merah merupakan kelompok Cluster_1 (Penjualan sedang) yang terdiri dari 4 items data dan titik warna merah merupakan kelompok Cluster_2 (Penjualan tertinggi) yang terdiri dari 1 item.

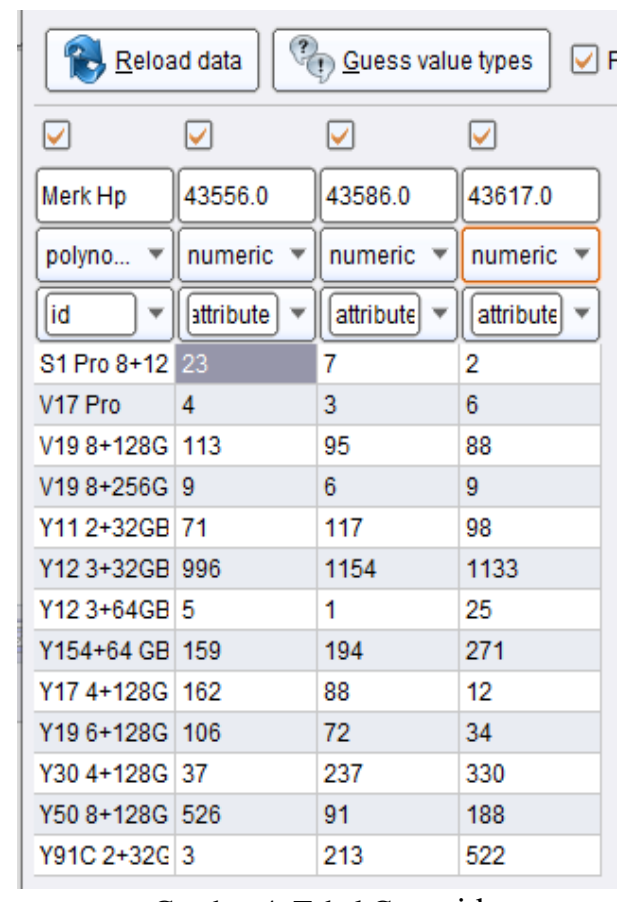

Gambar 4. Tabel Centroid

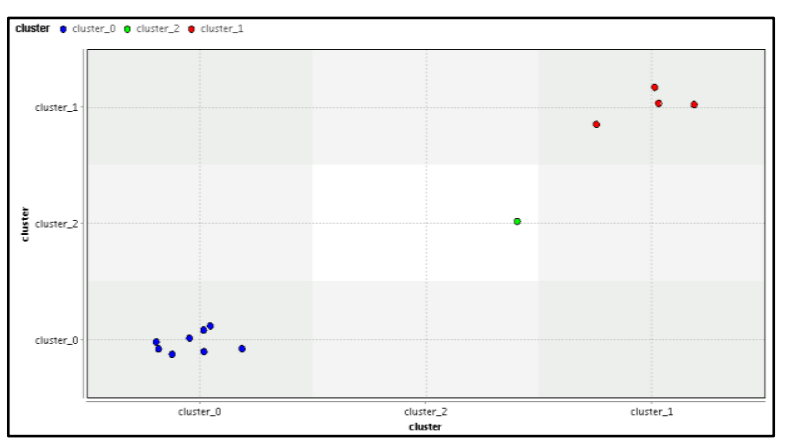

Gambar 5. Plot View Penjualan Smartphone Vivo di Pematangsiantar

\section{Kesimpulan}

Berdasarkan hasil penelitian dapat dilihat bahwa Ade Putri Mekaria Laila terpilih sebagai alternatif terbaik dengan nilai Optimasi 2,22692. Sehingga dapat disimpulkan Metode Moora merupakan metode yang cocok untuk mendapatkan hasil yang baik di dalam menentukan siswa yang layak menerima bantuan siswa miskin karena dapat mengolah data secara cepat dan tepat sesuai dengan yang diharapkan berdasarkan kriteria kriteria yang telah disajikan.

\section{Referensi}

[1] J. Martins, C. Costa, T. Oliveira, R. Gonçalves, and F. Branco, "How smartphone advertising influences consumers' purchase intention," Journal of Business Research, vol. 94, no. August 2017, pp. 378-387, 2019.

DOI: $\mathrm{xxxx}$

Lisensi: Creative Commons Attribution 4.0 International (CC BY 4.0) 
[2] Canalys, "Global smartphone market share Q2 2021," Canalys estimates (sell-in shipments), Smartphone Analysis, July 2021, 2021. [Online]. Available: https://www.canalys.com/newsroom/worldwide-smartphonemarket-q2-2021. [Accessed: 10-Aug-2021].

[3] A. Wanto et al., Data Mining : Algoritma dan Implementasi. Yayasan Kita Menulis, 2020.

[4] T. H. Sinaga, A. Wanto, I. Gunawan, S. Sumarno, and Z. M. Nasution, "Implementation of Data Mining Using C4.5 Algorithm on Customer Satisfaction in Tirta Lihou PDAM," Journal of Computer Networks, Architecture, and HighPerformance Computing, vol. 3, no. 1, pp. 9-20, 2021.

[5] D. Hartama, A. Perdana Windarto, and A. Wanto, "The Application of Data Mining in Determining Patterns of Interest of High School Graduates," Journal of Physics: Conference Series, vol. 1339, no. 1, pp. 1-6, 2019.

[6] I. S. Damanik, A. P. Windarto, A. Wanto, Poningsih, S. R. Andani, and W. Saputra, "Decision Tree Optimization in C4.5 Algorithm Using Genetic Algorithm," in Journal of Physics: Conference Series, 2019, vol. 1255, no. 1, pp. 1-6.

[7] M. G. Sadewo, A. P. Windarto, and A. Wanto, "Penerapan Algoritma Clustering dalam Mengelompokkan Banyaknya Desa/Kelurahan Menurut Upaya Antisipasi/ Mitigasi Bencana Alam Menurut Provinsi dengan K-Means," KOMIK (Konferensi Nasional Teknologi Informasi dan Komputer), vol. 2, no. 1, pp. 311-319, 2018.

[8] I. Parlina, A. P. Windarto, A. Wanto, and M. R. Lubis, "Memanfaatkan Algoritma K-Means dalam Menentukan Pegawai yang Layak Mengikuti Asessment Center untuk Clustering Program SDP," CESS (Journal of Computer Engineering System and Science), vol. 3, no. 1, pp. 87-93, 2018.

[9] W. Katrina, H. J. Damanik, F. Parhusip, D. Hartama, A. P. Windarto, and A. Wanto, "C.45 Classification Rules Model for Determining Students Level of Understanding of the Subject," Journal of Physics: Conference Series, vol. 1255, no. 1, pp. 16, Aug. 2019.

[10] H. Siahaan, H. Mawengkang, S. Efendi, A. Wanto, and A. Perdana Windarto, "Application of Classification Method C4.5 on Selection of Exemplary Teachers," Journal of Physics: Conference Series, vol. 1235, no. 1, pp. 1-7, Jun. 2019.

[11] C. Astria, A. P. Windarto, A. Wanto, and E. Irawan, "Metode K-Means pada Pengelompokan Wilayah Pendistribusian Listrik," Seminar Nasional Sains \& Teknologi Informasi (SENSASI), pp. 306-312, 2019.

[12] M. A. Hanafiah, A. Wanto, and P. B. Indonesia, "Implementation of Data Mining Algorithms for Grouping Poverty Lines by District/City in North Sumatra," International Journal of Information System \& Technology, vol. 3, no. 2, pp. 315-322, 2020.

[13] R. W. Sari, A. Wanto, and A. P. Windarto, "Implementasi Rapidminer Gengan Metode K-Means (Study Kasus: Imunisasi Campak Pada Balita Berdasarkan Provinsi)," KOMIK (Konferensi Nasional Teknologi Informasi dan Komputer), vol. 2, no. 1, pp. 224-230, 2018.

[14] S. R. Ningsih, I. S. Damanik, A. P. Windarto, H. S. Tambunan, J. Jalaluddin, and A. Wanto, "Analisis K-Medoids Dalam Pengelompokkan Penduduk Buta Huruf Menurut Provinsi," Prosiding Seminar Nasional Riset Information Science (SENARIS), vol. 1, pp. 721-730, Sep. 2019.

[15] M. Widyastuti, A. G. Fepdiani Simanjuntak, D. Hartama, A. P. Windarto, and A. Wanto, "Classification Model C.45 on Determining the Quality of Custumer Service in Bank BTN
Pematangsiantar Branch," Journal of Physics: Conference Series, vol. 1255, no. 1, pp. 1-5, Aug. 2019.

[16] A. Pradipta, D. Hartama, A. Wanto, S. Saifullah, and J. Jalaluddin, "The Application of Data Mining in Determining Timely Graduation Using the C45 Algorithm," IJISTECH (International Journal of Information System \& Technology), vol. 3, no. 1, pp. 31-36, 2019.

[17] T. Imandasari, E. Irawan, A. P. Windarto, and A. Wanto, "Algoritma Naive Bayes Dalam Klasifikasi Lokasi Pembangunan Sumber Air," Prosiding Seminar Nasional Riset Information Science (SENARIS), vol. 1, pp. 750-761, Sep. 2019.

18] I. Parlina et al., "Naive Bayes Algorithm Analysis to Determine the Percentage Level of visitors the Most Dominant Zoo Visit by Age Category," Journal of Physics: Conference Series, vol. 1255, no. 1, pp. 1-5, Aug. 2019.

[19] H. Siahaan, H. Mawengkang, S. Efendi, A. Wanto, and A. Perdana Windarto, "Application of Classification Method C4.5 on Selection of Exemplary Teachers," in Journal of Physics: Conference Series, 2019, vol. 1235, no. 1, pp. 1-7.

[20] S. Sudirman, A. P. Windarto, and A. Wanto, "Data Mining Tools | RapidMiner: K-Means Method on Clustering of Rice Crops by Province as Efforts to Stabilize Food Crops In Indonesia," IOP Conference Series: Materials Science and Engineering, vol. 420, no. 012089, pp. 1-8, 2018.

[21] S. Sundari, I. S. Damanik, A. P. Windarto, H. S. Tambunan, J. Jalaluddin, and A. Wanto, "Analisis K-Medoids Clustering Dalam Pengelompokkan Data Imunisasi Campak Balita di Indonesia," Prosiding Seminar Nasional Riset Information Science (SENARIS), vol. 1, pp. 687-696, Sep. 2019.

[22] N. Arminarahmah, A. D. GS, G. W. Bhawika, M. P. Dewi, and A. Wanto, "Mapping the Spread of Covid-19 in Asia Using Data Mining X-Means Algorithms," IOP Conf. Series: Materials Science and Engineering, vol. 1071, no. 012018, pp. $1-7,2021$.

[23] N. A. Febriyati, A. D. GS, and A. Wanto, "GRDP Growth Rate Clustering in Surabaya City uses the K- Means Algorithm," International Journal of Information System \& Technology, vol. 3, no. 2, pp. 276-283, 2020.

[24] J. Hutagalung, N. L. W. S. R. Ginantra, G. W. Bhawika, W. G. S. Parwita, A. Wanto, and P. D. Panjaitan, "COVID-19 Cases and Deaths in Southeast Asia Clustering using K-Means Algorithm," Journal of Physics: Conference Series, vol. 1783, no. 1, p. 012027, 2021.

[25] S. Handoko, F. Fauziah, and E. T. E. Handayani, "Implementasi Data Mining Untuk Menentukan Tingkat Penjualan Paket Data Telkomsel Menggunakan Metode KMeans Clustering," Jurnal Ilmiah Teknologi dan Rekayasa, vol. 25 , no. 1, pp. 76-88, 2020.

[26] Z. S. Younus et al., "Content-based image retrieval using PSO and k-means clustering algorithm," Arabian Journal of Geosciences, vol. 8, no. 8, pp. 6211-6224, 2015.

27] E. Prasetyo, Data Mining: Konsep dan Aplikasi menggunakan Matlab. Yogyakarta: Andi Offset, 2012.

[28] D. T. Larose, Discovering Knowledge in Data: An Introduction to Data Mining: Second Edition. New Jersey: John Wiley \& Sons, 2005.

[29] R. Primartha, Belajar Machine Learning Teori dan Praktik. Bandung: Informatika Bandung, 2018.

[30] T. Khotimah, "Pengelompokan Surat dalam Al Qur'an menggunakan Algortima K-Means," Jurnal Simetris, vol. 5, no. 1, pp. 83-88, 2014.

DOI: $\mathrm{xxxx}$

Lisensi: Creative Commons Attribution 4.0 International (CC BY 4.0) 